\title{
Burnout and job satisfaction among Turkish oceangoing seafarers
}

\author{
Leyla Tavacıoğlu ${ }^{1}$, Umut Taç² ${ }^{2}$ Özge Eski ${ }^{1}$, Neslihan Gökmen ${ }^{1}$ \\ ${ }^{1}$ Istanbul Technical University, Sahil Cad. Tuzla, Istanbul, Turkey \\ ${ }^{2}$ Namık Kemal University Vocational Collage of Social Sciences, Turkey
}

\begin{abstract}
Background: Seafaring includes a great variety of stressors that may let seafarers suffer from burnout syndrome. Job satisfaction is one of the most important factors affecting burnout. This study aims to determine the factors that affect job satisfaction and burnout levels of Turkish oceangoing seafarers who work actively on Turkish flagged ships.

Materials and methods: The questionnaire was applied to participants in a face-to-face mode or by e-mail. The first part of the questionnaire consisted of 12-item which included socio-demographic and health-related information. Thus, according to their health status and socio-demographics, seafarers were classified and their impact on job satisfaction and burnout were examined by nonparametric comparison of multivariate samples analysis. Maslach Burnout Inventory (MBI; 22 items) and Minnesota Satisfaction Questionnaire (MSQ; 20 items) were used. Spearman's rho correlation analysis was used to determine the relationship between the sub-factors of the scales. 203 seafarers, 133 of them deck/engine cadets and 186 of them working on deck, aged 18-60 years participated in the study.

Results: Negative correlation between job satisfaction and burnout was found by correlation analysis. Department and happiness while working on board were found as common important factors that vary according to both job satisfaction and burnout. According to these parameters, job satisfaction increased while burnout decreased or vice versa in both deck and engine and total.

Conclusions: According to the results, it was determined that deck officers are more prone to high burnout levels and low job satisfaction levels than the engine department. In addition, the results show that as happiness increases, job satisfaction increases and burnout decreases.
\end{abstract}

(Int Marit Health 2019; 70, 4: 232-238)

Key words: burnout, job satisfaction, seafarer, Maslach Burnout Inventory, Minnesota Satisfaction Questionnaire

\section{INTRODUCTION}

Working life has an important place in human life. Employees spend most of their time in the workplace. Today's intensive business relations force employees physically and mentally, and as a result, employees suffer from a syndrome called burnout. Various occupational groups face high levels of stress due to their organisational structure and working conditions [1]. Heavy workload and interpersonal mismatch in the working environment are important risk factors for burnout [2]. In spite of the technological progress, shorter contract duration on board and safety standards improvements in the maritime sector, seafarers are still under stressors, such as long working hours, separation from family, lack of social life, fatigue, sleep deprivation, work-related stress, piracy danger, maritime accident risk, multinational crew, diseases and limited recreation activity [3]. Due to these stressors, seafarers are prone to burnout.

Burnout was defined by Freudenberger for the first time in the mid-1970s. According to Freudenberger [4], burnout is the exhaustion occurring in the employee's energy as a result of failures, overloading, wear, loss of power and unmet expectations. Maslach [5], who made the most important 
contributions to the literature on the concept of burnout, developed the burnout inventory. According to Maslach [4], burnout is discussed in three dimensions. These are emotional exhaustion (EE), depersonalisation (DP) and personal accomplishment (PA) [5].

Emotional exhaustion is at the centre of burnout. In the emotional exhaustion feeling, which is generally related to work stress, the individual is in an emotionally intense working tempo. In this case, the individual is exposed to other people's demands and forces himself/herself. The main reason for the emergence of emotional exhaustion is overwork and conflict in the workplace [6]. Depersonalisation shows the interpersonal dimension of burnout. In the depersonalisation dimension, an employee uses humiliating statements against the workmates and individuals they serve and perform a cynical attitude. Under these behaviours, there are feelings of alienation and defence. Emotionally exhausted individuals limit their relationship with people and psychologically move away from people [7]. In the personal accomplishment, the employee feels insufficient and thinks that he/she is not competent enough to do the job. This concept refers to the tendency to evaluate oneself negatively. A decrease in motivation is observed. The individual makes self-assessment and thinks that there is no progress related to job and efforts are a waste of time [8]. Employees with burnout syndrome will be more inefficient and unsuccessful. They can perform worse than the officially expected results. On the other hand, they may be more unwilling to help their colleagues. Therefore, they may lose their position in the organisation [9].

Job satisfaction is a concept directly related to burnout. Job satisfaction is defined as the employees' perception of the work and their emotional response to this perception and the degree of satisfaction of their needs [10]. Job satisfaction is the satisfaction or dissatisfaction that employees feel towards their jobs. While a person with high job satisfaction has a positive feeling about the job, the person with low job satisfaction has a negative feeling about the job [11]. There is a linear relationship between job satisfaction and professional performance. As job satisfaction increases or decreases, the professional performance increases or decreases, respectively. The social environment at work, working conditions, wages, rewards, the nature of the work and the clarity of job descriptions affect job satisfaction [12].

A limited number of studies on burnout or job satisfaction among seafarers are obtained from the literature review in the maritime domain. Previous studies show that seafaring includes high stress and serious risks. Work stress, fatigue, and individual isolation have negative consequences on the seafarers which may lead to burnout [13]. Intense work pressure and separation from family have an impact on the emotional health of seafarers [14]. Intensive and long working hours increase depersonalisation [15]. Less than 6 months of working time, low stress and quality of sleep are the factors in the reduction of burnout [16]. The study conducted among Croatian seafarers shows that they are most satisfied with the payment, and least satisfied with the achieved benefits and work organisation on board. The study also shows that separation from family and working conditions on board are the primary sources of job dissatisfaction [3]. Work stress, rewards, dispositions, and job design also influence job satisfaction. Job satisfaction positively correlates with job performance.

This is the first study to assess the relationship between job satisfaction and burnout levels of seafarers. In this study, it is aimed to determine the factors that affect the job satisfaction and burnout levels of Turkish oceangoing seafarers who work actively on Turkish flagged ships. This paper is divided into four chapters. In the introduction part, the definition and dimensions of burnout, the statement of job satisfaction is given and the literature is reviewed. In the second part, the data collection process and the statistical method are explained. In the third part, results are introduced. Lastly, a brief discussion and conclusion are presented.

\section{MATERIALS AND METHODS}

\section{DATA COLLECTION AND SAMPLE}

Roasoft online calculator was used for sample size calculation. In Turkey by the end of March 2018, the number of actively working seafarers was 29345 . According to population statistics, the sample size was calculated at 269 with $90 \%$ confidence level and $5 \%$ error. 250 participants were selected randomly. The sample was recruited by sharing the questionnaires online with Google Forms (e-mail) and by conducting it face-to-face. 203 seafarers responded (response rate: 81\%). The data are collected when the participants are on board. Seafarers participating in the study are working on oil tankers and the contract period is between 3 and 6 months. The questionnaire consists of three parts. First part includes demographic characteristics of the participants. The second part of the questionnaire includes burnout questions and finally job satisfaction questions were asked in the third part. To evaluate burnout and job satisfaction, the Maslach Burnout Inventory (MBI) and Minnesota Job Satisfaction Scale (MJSS) were used. Cronbach-Alpha internal consistency coefficient was found to be 0.869 for $\mathrm{MBI}(\mathrm{EE}, \mathrm{r}=0.868, \mathrm{DP}, \mathrm{r}=0.705, \mathrm{PA}, \mathrm{r}=0.766$ ) and 0.917 for MJSS (Internal satisfaction, $r=0.879$, External satisfaction, $r=0.832$ ). This coefficient was appropriate and therefore, could be used in this study.

The demographics of the participants were measured with thirteen questions such as age, gender, education, etc., which could be seen in Table 1. 
Table 1. Demographic characteristics of the participants $(N=203)$

\begin{tabular}{|c|c|c|c|}
\hline & & $\mathbf{N}$ & $\%$ \\
\hline \multirow[t]{2}{*}{ Age [years] } & $18-30$ & 158 & $77.8 \%$ \\
\hline & $30+$ & 45 & $22.2 \%$ \\
\hline \multirow[t]{2}{*}{ Gender } & Female & 29 & $14.3 \%$ \\
\hline & Male & 174 & $85.7 \%$ \\
\hline \multirow[t]{2}{*}{ Education } & High school/Associate degree & 13 & $6.4 \%$ \\
\hline & Bachelor degree/Graduate level & 190 & 93.65 \\
\hline \multirow[t]{3}{*}{ Parental education - Mother } & Primary school & 92 & $45.8 \%$ \\
\hline & High school & 61 & $30.3 \%$ \\
\hline & Associate/Bachelor degree/Graduate level & 48 & $23.9 \%$ \\
\hline \multirow[t]{3}{*}{ Parental education - Father } & Primary school & 70 & $34.5 \%$ \\
\hline & High school & 48 & $23.6 \%$ \\
\hline & Associate bachelor degree/Graduate level & 85 & $41.9 \%$ \\
\hline \multirow[t]{2}{*}{ Department } & Deck & 186 & $91.6 \%$ \\
\hline & Engine & 17 & $8.4 \%$ \\
\hline \multirow[t]{4}{*}{ Experience (on board) } & 3-6 months & 54 & $26.7 \%$ \\
\hline & $6-12$ months & 80 & $39.6 \%$ \\
\hline & $1-3$ years & 24 & $11.9 \%$ \\
\hline & 3 years and over & 44 & $21.8 \%$ \\
\hline \multirow[t]{2}{*}{ Position } & Deck/Engine cadet & 133 & $65.6 \%$ \\
\hline & Officer/Engineer & 70 & $34.4 \%$ \\
\hline \multirow[t]{4}{*}{ Disliked work when working on board } & Staff problems & 81 & $40.5 \%$ \\
\hline & Document processing & 79 & $39.5 \%$ \\
\hline & Operational processing & 14 & $7.0 \%$ \\
\hline & Other & 26 & $13.0 \%$ \\
\hline \multirow[t]{5}{*}{ Are you happy to work on board? } & I'm not happy at all & 21 & $10.4 \%$ \\
\hline & I'm a little happy & 25 & $12.4 \%$ \\
\hline & Neither happy nor unhappy & 65 & $32.2 \%$ \\
\hline & I'm happy & 68 & $33.7 \%$ \\
\hline & I'm so happy & 23 & $11.4 \%$ \\
\hline \multirow[t]{2}{*}{ Do you have any medication? } & No & 191 & $94.1 \%$ \\
\hline & Yes & 12 & $5.9 \%$ \\
\hline \multirow{4}{*}{$\begin{array}{l}\text { What was the last reason you went } \\
\text { to the doctor? }\end{array}$} & No & 34 & $16.7 \%$ \\
\hline & Pain & 52 & $25.6 \%$ \\
\hline & Chronic disease & 31 & $15.3 \%$ \\
\hline & Other (psychological etc.) & 86 & $42.4 \%$ \\
\hline
\end{tabular}


Table 2. Distributions of scales (MBI and MJSS)

\begin{tabular}{llll}
\hline & N & Mean \pm SD & Median (min-max) \\
\hline Emotional exhaustion & 203 & $1.72 \pm 0.8$ & $1.67(0-4)$ \\
Depersonalisation & 203 & $1.42 \pm 0.85$ & $1.40(0-4)$ \\
Personal accomplishment & 203 & $1.56 \pm 0.71$ & $1.63(0-4)$ \\
Burnout & 203 & $1.59 \pm 0.6$ & $1.64(0.25-3.82)$ \\
Internal satisfaction & 203 & $3.53 \pm 0.71$ & $3.58(1-4.92)$ \\
External satisfaction & 203 & $3.31 \pm 0.78$ & $3.38(1.13-5.00)$ \\
Job satisfaction & 203 & $3.44 \pm 0.69$ & $3.50(1.40-4.85)$
\end{tabular}

MBI - Maslach Burnout Inventory; MJSS - Minnesota Job Satisfaction Scale; SD - standard deviation; min - minimum; max - maximum

Table 3. Correlation analysis between scales

\begin{tabular}{llll}
\hline $\mathbf{r}$ & Internal satisfaction & External satisfaction & Job satisfaction \\
\hline Emotional exhaustion & $-0.550^{*}$ & $-0.428^{*}$ & $-0.532^{*}$ \\
Depersonalization & $-0.360^{*}$ & $-0.287^{*}$ & $-0.351^{*}$ \\
Personal accomplishment & $-0.417^{*}$ & $-0.331^{*}$ & $-0.415^{*}$ \\
Burnout & $-0.610^{*}$ & $-0.479^{*}$ & $-0.595^{*}$
\end{tabular}

${ }^{*} \mathrm{p}<0.001$

Maslach Burnout Inventory has three sub-dimensions named emotional exhaustion, depersonalisation, personal accomplishment. Emotional exhaustion refers to emotions that are emotionally depleted by an individual's excessive long-term interaction with other people. Depersonalisation is that employees behave like objects to the people they serve, make disparaging remarks, and show an indifferent, cynical attitude. Personal accomplishment defines a person's feelings of competence and success in their work.

Minnesota Job Satisfaction Scale consists of fire-point Likert 20 items as follows completely dissatisfied is 1, dissatisfied is 2 , neither dissatisfied nor satisfied is 3 , satisfied is 4 and completely satisfied is 5 . The scale has two sub-dimensions named internal and external satisfaction. Internal satisfaction consists of elements related to the internal quality of the job, such as success, recognition or appreciation of the internal factors, the job itself, job responsibility, promotion and change of duty due to promotion. External satisfaction consists of elements related to the work environment, such as corporate policy and management, the manner of supervision, relations with managers, colleagues and subordinates, working conditions, and wages. To summarise total and sub-dimension scores descriptive statistics were used (Table 2).

\section{STATISTICAL ANALYSIS}

Descriptive statistics were calculated for continuous variables (mean, standard deviation [SD], minimum, maximum, median) and categorical variables (N, \%). Spearman's rho correlation analysis was used to determine two non-normally distributed variables. It is shown in Tables 3 and 4, and Figures 1 and 2. To investigate the effects of demographics on both burnout and job satisfaction levels, "Nonparametric Comparison of Multivariate Samples Analysis" was used due to the lack of assumptions. Homogeneity (Box's test, $p<0.05$, Levene's test, $p<0.05$ ) and multivariate normal distribution (Shapiro Wilk, $p<0.05$ ) assumptions are not provided. It is shown in Table 4. The statistical significance level was determined as 0.05 . The analysis was conducted by utilising SPSS 24.0 (Statistical Package for the Social Sciences) and R Studio. Nonparametric Comparison of Multivariate Samples Analysis is utilised by "npmv" package which provides a nonparametric approach to multivariate inference [17].

\section{RESULTS}

Demographics were evaluated by frequencies and column percentages. According to Table 1, 29 (14.3\%) women and 174 (85.7\%) men participated in this study. 158 of 203 participants (77.8\%) are between 18 and 30 years. The educational status of 190 of 203 participants (93.6\%) is a bachelor's degree and graduate level. Mother's education status is mostly primary school, whereas father's education status is mostly associate and bachelor's degree and graduate level. 186 (91.6\%) participants are working in the deck department. 80 of 203 participants (39.6\%) have 
Table 4. Nonparametric comparison of multivariate samples analysis for demographics

\begin{tabular}{|c|c|c|c|c|c|c|c|}
\hline & & \multirow[t]{2}{*}{$\mathbf{N}$} & \multirow{2}{*}{$\begin{array}{l}\text { Burnout } \\
\text { Mean } \pm \text { SD } \\
\text { (relative effect) }\end{array}$} & \multirow{2}{*}{$\begin{array}{l}\text { Job satisfaction } \\
\text { Mean } \pm \text { SD } \\
\text { (relative effect) }\end{array}$} & \multirow{2}{*}{$\begin{array}{l}\text { Wilks } \\
\text { Lambda }\end{array}$} & \multirow[t]{2}{*}{$\mathbf{p}$} & \multirow{2}{*}{$\begin{array}{l}\text { Permutation } \\
\text { test }-p\end{array}$} \\
\hline & & & & & & & \\
\hline \multirow[t]{2}{*}{ Department } & Deck & 186 & $1.65 \pm 0.59(0.779)$ & $3.41 \pm 0.69(0.320)$ & 5.505 & 0.005 & 0.004 \\
\hline & Engine & 17 & $1.04 \pm 0.48(0.220)$ & $3.82 \pm 0.53(0.679)$ & & & \\
\hline \multirow{5}{*}{$\begin{array}{l}\text { Are you } \\
\text { happy to work } \\
\text { on board? }\end{array}$} & I'm not happy at all & 21 & $2.6 \pm 0.47(0.914)$ & $2.44 \pm 0.58(0.130)$ & 13.380 & $<0.001$ & $<0.001$ \\
\hline & I'm a little happy & 25 & $1.79 \pm 0.47(0.624)$ & $3.36 \pm 0.56(0.453)$ & & & \\
\hline & $\begin{array}{l}\text { Neither happy nor } \\
\text { unhappy }\end{array}$ & 65 & $1.67 \pm 0.45(0.558)$ & $3.35 \pm 0.60(0.439)$ & & & \\
\hline & I'm happy & 68 & $1.06 \pm 0.44(0.392)$ & $3.67 \pm 0.56(0.600)$ & & & \\
\hline & I'm so happy & 23 & $1.59 \pm 0.69(0.240)$ & $3.84 \pm 0.68(0.692)$ & & & \\
\hline
\end{tabular}

SD - standard deviation

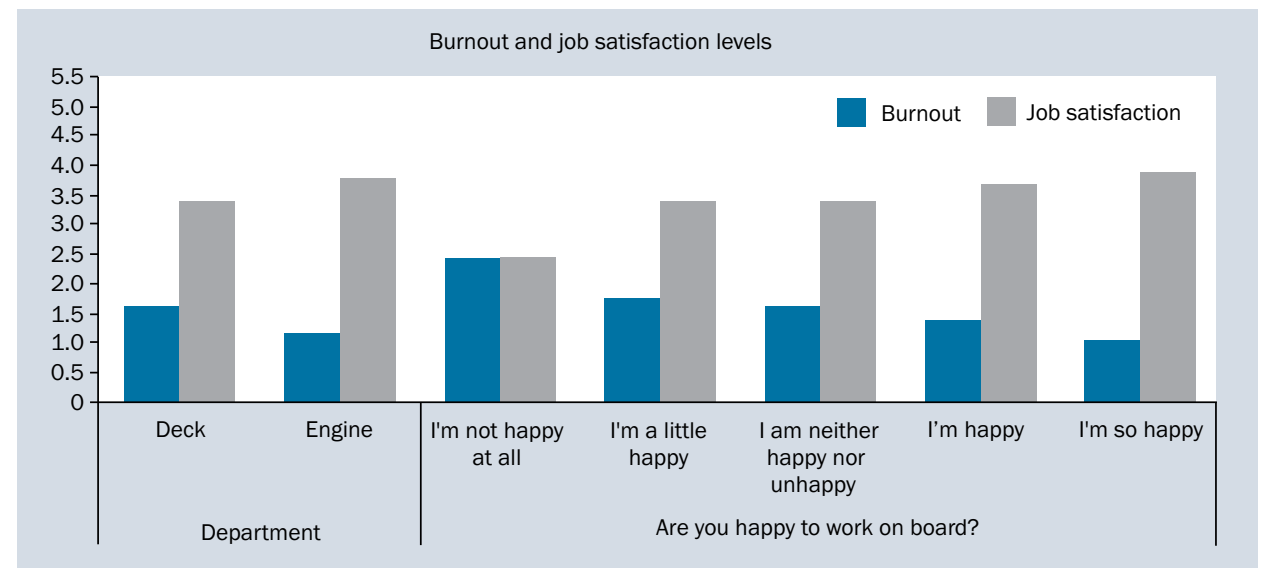

Figure 1. The significant differences between burnout and job satisfaction scores in common

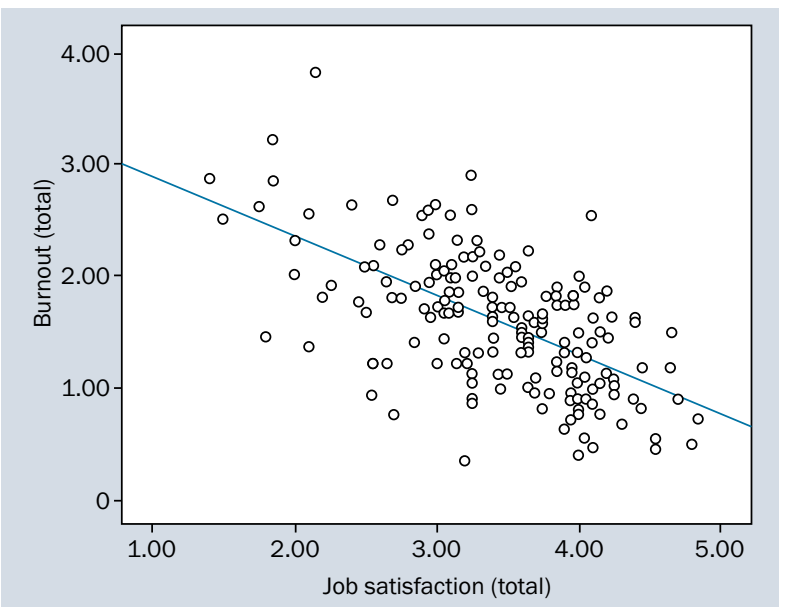

Figure 2. Scatter plot of burnout and job satisfaction relationship

worked on board for 6-12 months. 133 of 203 participants (65.6\%) are deck/engine cadets. 79 (39.5\%) participants disliked document processing when they are working on board and 68 (33.7\%) participants are happy to work on board. 86 (42.4\%) of them went doctor for other reasons like psychological etc.

Distributions of scales are shown in Table 2. All the sub-dimensions and total burnout's scores display similar distributions between 0 and 4. Similarly, job satisfaction scores and sub-dimensions are changed between 1 to 5 and show similar distributions.

According to correlation analysis, there is a significant relationship between all paired scales (Spearman's rho, $p<0.05)$. There are negative moderate statistically significant correlations between emotional exhaustion and internal satisfaction, external satisfaction, job satisfaction. There is a negative weak correlation between depersonalisation and internal satisfaction, external satisfaction, job satisfaction. There is a negative weak correlation between personal accomplishment and internal satisfaction, external satisfaction, job satisfaction. There are negative moderate statistically significant correlations between burnout and internal satisfaction, external satisfaction, job satisfaction (Table 3). 
Figure 2 supports the correlation results and shows a negative relationship between burnout and job satisfaction in a moderate way.

The significant results were presented in Table 4 for comparison of burnout levels and job satisfaction according to demographics. The department and happiness effect is highly significant (Wilks Lambda, $p<0.05$ ). The empirical nonparametric relative department effect and happiness effect are listed for burnout and job satisfaction in Table 4. The probability that a randomly chosen from deck department exhibits a larger percentage of burnout than a randomly chosen person from seafarers (including deck) is 0.779 . Similarly, the probability that a randomly chosen from not happy at all during working on board exhibits a larger percentage of burnout than a randomly chosen person from seafarers (including not happy at all) is 0.914 . To implement all the pairwise comparisons according to happiness status "ssnonpartest" function is used to provide a more detailed comparison using a subset algorithm [17]. The multiple comparisons of all happiness levels and all variables are shown significant results (Wilks Lambda, $p<0.05$ ). The point that draws attention is that while the burnout relative effect of not happy at all ones is high, the job satisfaction relative effect of so happy ones is high.

To sum up the results, Figure 1 shows the significant differences between burnout and job satisfaction levels in terms of department and happiness status. According to the figure, the negative relationship is noticeable.

To prevent the instability caused by the sample (deck $\mathrm{N}=186$ and engine $\mathrm{N}=17$ ) and taking into account the results of the multivariate analysis which were found to be significant, the data was divided into two parts as deck and engine. To show the relationship between job satisfaction and burnout levels, correlation analysis was performed on two divided data. According to correlation analysis, there is a significant relationship between job satisfaction and burnout both in deck and engine groups (Spearman's rho, $p<0.05)$. The relationship is found negative and moderate. The moderate level relationship in the engine is found to be stronger than the deck with $-0.864(p<0.001)$ correlation coefficient (Table 5).

Figure 3 supports the correlation results and shows a negative relationship between burnout and job satisfaction in a moderate way separately both deck and engine department.

\section{DISCUSSION AND CONCLUSIONS}

The main purpose of the study is to examine the relationship between seafarers' burnout and job satisfaction levels. The negative statistically significant relationship between burnout and job satisfaction is found and supported by work conditions and happiness conditions while working on board.

Working on board is difficult and complex; being away from home and loved ones, fatigue, long working hours, limited space, inadequate sleep and multinational factors [18]. This is also related to the happiness of the seafarers, while the satisfaction of the seafarers who work happily high and the burnout is low. In a previous study that includ-

Table 5. Correlation analysis between job satisfaction and burnout (according to department)

\begin{tabular}{llll}
\hline & \multicolumn{3}{l}{ Job satisfaction } \\
\cline { 2 - 4 } & $\mathbf{r}$ & Deck & Engine \\
\hline Burnout & Deck & $-0.572^{*}$ & \\
& Engine & & $-0.864^{*}$
\end{tabular}

${ }^{*} p<0.001$

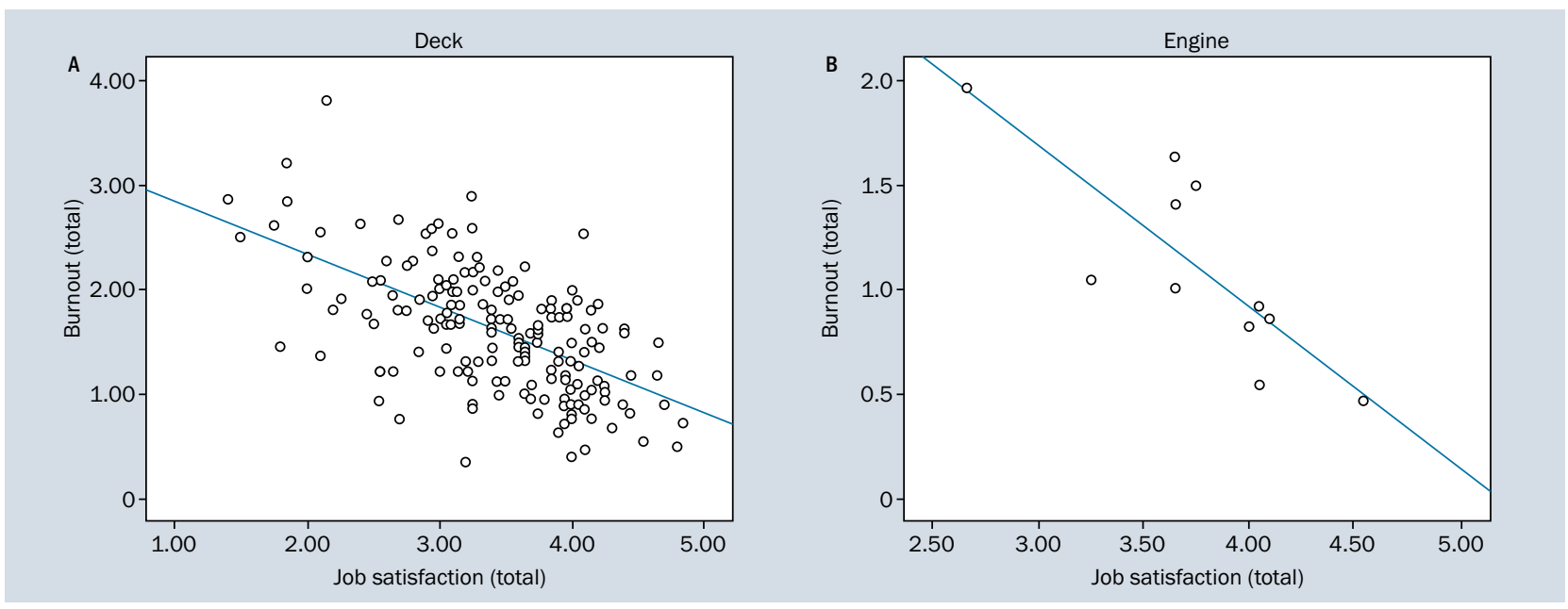

Figure 3. Scatter plot of burnout and job satisfaction relationship according to department; A. Deck; B. Engine 
ed 136 people who work on average 36 hours per week, showed a negative correlation between happiness during work activities and burnout [19].

As the working conditions of seafarers are rough, intention to leave occurs. While the age increases, the intention to leave decreases. Similarly, as the age increases, job satisfaction increases and burnout decreases. In this study, the department is found to be an important factor affecting job satisfaction and burnout. The study that targeted 139 deck and engineering officers showed similar results. The average of chief engineer has a higher job satisfaction level than deck officers [20].

The first limitation of the study was a sample in terms of gender. Our participants are mostly men. Therefore, we cannot generalise our findings to women. The second limitation of the study is the fact that the participants are mostly working on deck and the participation of deck/ /engine cadets are more than officers. In future studies, the sample could be selected more from deck department and officers. The last point is all the participants are from Turkey. The research can be expanded by selecting multinational seafarers from different countries. In the following studies, comparisons can be made by measuring psychophysiological data.

\section{REFERENCES}

1. Droogenbroeck FV, Spruyt B, Vanroelen C. Burnout among senior teachers: Investigating the role of workload and interpersonal relationships at work. Teaching and Teacher Education. 2014; 43: 99-109, doi: 10.1016/j.tate.2014.07.005.

2. Demerouti E, Bakker AB, Nachreiner F, et al. The job demands-resources model of burnout. J Appl Psychol. 2001; 86(3): 499-512, indexed in Pubmed: 11419809.

3. Slišković A, Penezić Z. Descriptive study of job satisfaction and job dissatisfaction in a sample of Croatian seafarers. Int Marit Health. 2015; 66(2): 97-105, doi: 10.5603/IMH.2015.0023, indexed in Pubmed: 26119680.

4. Freudenberger H. Staff burn-out. J Social Issues. 1974; 30(1): 159-165, doi: 10.1111/j.1540-4560.1974.tb00706.x.

5. Maslach C, Goldberg J. Prevention of burnout: New perspectives. Applied Preventive Psychology. 1998; 7(1): 63-74, doi: 10.1016/ s0962-1849(98)80022-x.
6. Lewin J, Sager J. A process model of burnout among salespeople: Some new thoughts. J Business Res. 2007; 60(12): 1216-1224, doi: 10.1016/j.jbusres.2007.04.009.

7. Seligman M. Learned optimism: how to change your mind and your life. Vintage 2006: ISBN-10: 1400078393. ISBN-13: 9781400078394.

8. Leiter M, Maslach C. The impact of interpersonal environment on burnout and organizational commitment. J Organizational Behavior. 1988; 9(4): 297-308, doi: 10.1002/job.4030090402.

9. Bakker A, Demerouti E. The job demands resources model: state of the art. J Managerial Psychology. 2007; 22(3): 309-328, doi: 10.1108/02683940710733115.

10. Federici R, Skaalvik E. Principal self-efficacy: relations with burnout, job satisfaction and motivation to quit. Social Psychology Education. 2012; 15(3): 295-320, doi: 10.1007/s11218-012-9183-5.

11. Robbins SP, Judge TA. Organizational behavior. 15th Edition. Pearson Education, Inc., New Jersey 2012: ISBN-10: 0-13-283487-2. ISBN-13: 978-0-13-283487-2.

12. Ting $Y$. Determinants of job satisfaction of federal government employees. Public Personnel Management. 1997; 26(3): 313-334, doi: 10.1177/009102609702600302.

13. Jeżewska M, Leszczyńska I, Jaremin B. Work-related stress at sea self estimation by maritime students and officers. Int Marit Health. 2006; 57(1-4): 66-75, indexed in Pubmed: 17312695.

14. Borovnik M. Occupational health and safety of merchant seafarers from Kiribati and Tuvalu. Asia Pac Viewp. 2011; 52(3): 333-346, doi: 10.1111/j.1467-8373.2011.01459.x, indexed in Pubmed: 22216477.

15. Oldenburg M, Jensen $H J$, Wegner R. Burnout syndrome in seafarers in the merchant marine service. IntArch Occup Environ Health. 2013;86(4): 407-416, doi: 10.1007/s00420-012-0771-7, indexed in Pubmed: 22526089.

16. Wu S, Chai W, Zhang J, et al. [Status of job burnout and its influential factors in seafarers]. Zhonghua Lao Dong Wei Sheng Zhi Ye Bing Za Zhi. 2014; 32(6): 411-414, indexed in Pubmed: 25169221.

17. Burchett W, Ellis A, Harrar S, et al. Nonparametric Inference for Multivariate Data: The R Package npmv. J Statistical Software. 2017; 76(4), doi: 10.18637/jss.v076.i04.

18. Bakker AB, Oerlemans WGM. Momentary work happiness as a function of enduring burnout and work engagement. J Psychol. 2016; 150(6): 755-778, doi: 10.1080/00223980.2016.1182888, indexed in Pubmed: 27223847.

19. Tavacioglu L, Gökmen N, Eski Ö, et al. A research as mobbing examination in maritime sector. Bilge Int J Science Techn Res. 2018; 2: 32-39, doi: 10.30516/bilgesci.489095.

20. Kim JH, Jang SN. The relationship between job stress, job satisfaction, and the symptom checklist-90-revision (SCL-90-R) in marine officers on board. J Prev Med Public Health. 2016; 49(6): 376-385, doi: 10.3961/jpmph.16.046, indexed in Pubmed: 27951630. 